\title{
Estimating the Direct Costs of Outpatient Opioid Prescriptions: A Retrospective Analysis of Data from the Rhode Island Prescription Drug Monitoring Program
}

\author{
Hilary Aroke, MD, MPH; Ashley Buchanan, DrPH, MS; Xuerong Wen, PhD, MS; \\ Peter Ragosta, RPh; Jennifer Koziol, MPH; and Stephen Kogut, PhD, MBA, RPh
}

\begin{abstract}
BACKGROUND: Overuse and misuse of prescription opioids is associated with increased morbidity and mortality and places a significant cost burden on health systems.

OBJECTIVE: To estimate annual statewide spending for prescription opioids in Rhode Island.

METHODS: A cross-sectional study of opioids dispensed from retail pharmacies using data from the Rhode Island Prescription Drug Monitoring Program (PDMP) was performed. The study sample consisted of 651,227 opioid prescriptions dispensed to 197,062 patients between January 1, 2015, and December 31, 2015. The mean, median, and total cost of opioid use was estimated using prescription dispensings and patients as units of analysis. A generalized linear model with gamma distribution with an identity link function, and separately with a log link function, was used to estimate the absolute and relative differences in per-patient annual adjusted average opioid prescription cost, respectively, by potential predictors.
\end{abstract}

RESULTS: The estimated 2015 annual expenditure for opioid prescriptions in Rhode Island was $\$ 44,271,827$. The average and median costs of an opioid prescription were $\$ 67.98$ (SD \$210.91) and \$21.08 (quartile 1 to quartile $3=\$ 7.65-\$ 47.51$ ), respectively. Prescriptions for branded opioid products accounted for $\$ 17,380,279.05$, which was approximately $39.3 \%$ of overall spending, although only $6 \%$ of all opioids dispensed were for branded drugs. On average, patients aged 45-54 years and 55-64 years had overall adjusted spending for opioids that were $1.53(95 \% \mathrm{Cl}=1.49$ $1.57)$ and $1.75(95 \% \mathrm{Cl}=1.71-1.80)$ times higher than patients aged 65 years and older, respectively. Per patient Medicaid and Medicare average annual spending for opioid prescriptions were $1.19(95 \% \mathrm{Cl}=1.16-1.22)$ and $2.01(95 \% \mathrm{Cl}=1.96-2.06)$ times higher than commercial insurance spending, respectively. Annual opioid prescription spending was 2.01 $(95 \% \mathrm{Cl}=1.98-2.04)$ and $1.50(95 \% \mathrm{Cl}=1.45-1.55)$ times higher among patients who also had at least 1 dispensing of a benzodiazepine or sympathomimetic stimulant, respectively. Average total spending for prescription opioids per patient increased with the average daily dosage: from 3-fold for patients using 50-90 morphine milligrams equivalent (MME) daily to 22-fold for those receiving 90 or more MME daily compared with those receiving less than 50 MME daily.

CONCLUSIONS: This study provides the first estimate of the statewide direct cost burden of prescription opioid use using PDMP data and standardized pricing benchmarks. Total annual cost increased with age up to 65 years, mean daily dose, and concurrent use of benzodiazepines or stimulants. Commercial insurance bore the majority of the cost of prescription opioid use, but cost per patient was highest among Medicare beneficiaries. In addition to reducing harms associated with opioid overuse and misuse, substantial cost savings could be realized by reducing unnecessary opioid use, especially among middle-aged adults.

J Manag Care Spec Pharm. 2018;24(3):214-24

Copyright $\odot 2018$, Academy of Managed Care Pharmacy. All rights reserved.

\section{What is already known about this subject}

Overuse of prescription opioids is associated with increased morbidity and mortality and places a significant cost burden on health systems.

Total U.S. spending for opioid analgesic prescriptions increased substantially from $\$ 2.3$ billion in 1999 to $\$ 7.4$ billion in 2012

\section{What this study adds}

Total 2015 annual retail expenditure for opioid analgesic prescriptions in Rhode Island was estimated at \$44,271,827.

Commercial insurance bore the majority of the cost of prescription opioid use, but cost per patient was highest among Medicare beneficiaries.

More than $10 \%$ of patients paid for at least 1 opioid prescription with cash, but cash payment accounted for only $5.1 \%$ of the total annual prescription opioid expenditure.

$\mathrm{P}$ ain is one of the most common reasons for an outpatient office visit. ${ }^{1-3}$ According to a 2011 Institute of Medicine report, approximately 100 million adults in the United States suffer from chronic pain each year. ${ }^{4}$ Prescription opioid analgesics are commonly used to treat a variety of painful conditions that range from acute injury to palliative care for terminal illness. In 2012, U.S. health care providers issued over 259 million opioid prescriptions. ${ }^{5}$ Higher rates of opioid prescribing over the past 2 to 3 decades may be attributed in part to historical changes in pain management guidelines, the Joint Commission requirements for routine pain assessment, promotion by the pharmaceutical industry, and changes in reimbursement and out-of-pocket payment for prescription opioids. ${ }^{6-10}$

Although use of prescription opioid analgesics is often clinically necessary, their addictive and euphoric properties easily result in misuse and often lead to opioid use disorders. In recent years, deaths from drug overdose have increased dramatically, exceeding the number of deaths from motor vehicle accidents, and have become the leading cause of accidental death in the United States. ${ }^{5,11-13}$ In 2015 alone, drug overdose 
was responsible for 52,404 deaths, with 33,091 (63.2\%) associated with opioids. More than $60 \%$ of opioids involved in drug overdose deaths are prescription opioids. ${ }^{14,15}$ Benzodiazepines and opioids are often prescribed together, which has the potential risk of respiratory depression and overdose death. ${ }^{16-18}$ The U.S. Food and Drug Administration recently issued a boxed warning limiting the concurrent use of opioids and benzodiazepines or other central nervous system depressants, adding to recent changes in opioid prescribing guidelines. ${ }^{19-21}$

Currently, all state legislatures, with the exception of Missouri, have implemented state-run prescription drug monitoring programs (PDMPs) that are designed to identify and track the prescribing and dispensing of controlled substances, including prescription opioids dispensed from retail pharmacies. The purpose of these PDMPs is to alert prescribers of controlled substances issued by other practitioners and to promote appropriate prescribing practices by making opioid medication history accessible to prescribers and pharmacists at the point of care delivery.22 In most states, including Rhode Island, prescription drugs that are monitored are classified as Schedule II, III, and IV and opioid medications within Schedule V on the Drug Enforcement Administration's (DEA) 5-tiered schedule. Drugs are assigned to 1 of these categories by the DEA based on their medicinal value and the potential for abuse and diversion.

While significant attention has been directed towards the health consequences of opioid prescribing, little has been published on the associated health care costs..$^{14,23-25}$ The annual societal cost of pain in terms of medical care and lost productivity in the United States has been estimated at $\$ 635$ billion in 2010 dollars. ${ }^{4}$ White et al. (2005) estimated that the total health care costs per patient varied from $\$ 15,884$ to $\$ 18,388$ among patients with opioid use disorder diagnoses compared with only $\$ 1,830-\$ 2,210$ among a similar group of patients with no documented history of such disorders. ${ }^{26}$ Recent publications of costs related to opioid use have examined trends in expenditures using national Medicare and Medical Expenditure Panel Survey data. ${ }^{23,27}$ Zhou et al. (2016) estimated that total U.S. spending for opioid analgesic prescriptions increased substantially from $\$ 2.3$ billion in 1999 to $\$ 7.4$ billion in 2012, ${ }^{27}$ while Stagnitti et al. (2015) estimated the total expenses for outpatient prescription opioids at $\$ 9.0$ billion in 2012, an increase of $120 \%$ from $2002 .{ }^{28}$

The effect of opioid use on statewide health systems can be quantified in terms of the direct cost of prescriptions to payers. To date, no published studies have examined state-level direct costs associated with prescription opioid dispensings from retail pharmacies across different age groups, gender, medication types, and sources of payment. In this study, data from the Rhode Island PDMP were used to estimate the distribution of the direct cost of opioid prescriptions dispensed by retail pharmacies in Rhode Island during the calendar year 2015.
The goal of this analysis was to determine the total 2015 annual expenditure for prescription opioid analgesics in Rhode Island as captured in the PDMP. The proportions of spending associated with cash payment and by public and private payers were determined. In additon, we evaluated if gender, age group, payment type, or use of benzodiazepines or stimulants were associated with the total annual prescription opioid cost per patient. Understanding these factors may help elucidate the extent of opioid use statewide and provide support for efforts by providers, public health regulators, and payers to reduce the misuse of prescription opioid analgesics. ${ }^{29}$

\section{Methods}

\section{Study Design and Data Source}

A cross-sectional study was conducted to examine annual opioid use and spending by patient and by type of opioid medication dispensed using data from the 2015 Rhode Island PDMP. For this study, opioid medication included all DEA Schedule II-IV prescription medications dispensed by retail pharmacies licensed within the state.

Since June 28, 2016, Rhode Island state law requires pharmacies to monitor Schedule II-V controlled substances. Pharmacies holding a retail license in Rhode Island are legally required to electronically report all monitored controlled substances filled within 1 business day of the prescription being dispensed to the patient. This requirement includes independent pharmacies, chain pharmacies, food stores, and mass merchandisers but not substance abuse treatment programs, in-patient hospital pharmacy services, and correctional facilities. A commercial vendor links multiple prescriptions for each patient using probabilistic techniques based on the patient's name, date of birth, and street address. ${ }^{30,31}$ Similarly, all prescriptions written by each provider and dispensed by the pharmacist are linked by unique prescriber DEA numbers.

The data provided by the Rhode Island Department of Health for our study included only deidentified patient, prescriber, and dispensing pharmacy information. Available information included patient age (in years), gender, a unique prescriber and dispensing pharmacy identifier, the National Drug Code (NDC) number, product name, strength, formulation, and therapeutic class code of each prescription, as well as the number of days supplied, metric quantity dispensed, method of payment, and date the prescription was filled. The pharmacist estimated days supply based on the quantity prescribed and the daily dosage. The payment type field was populated by the dispensing pharmacist, and a payment type of "commercial" was presumably incorrectly assigned for many older adults who were more likely enrolled in a Medicare plan. Therefore, for patients who were aged 65 years or older with a payment type of commercial, their payment type was reclassified as Medicare. 


\section{FIGURE 1 Sample Identification Flowchart}

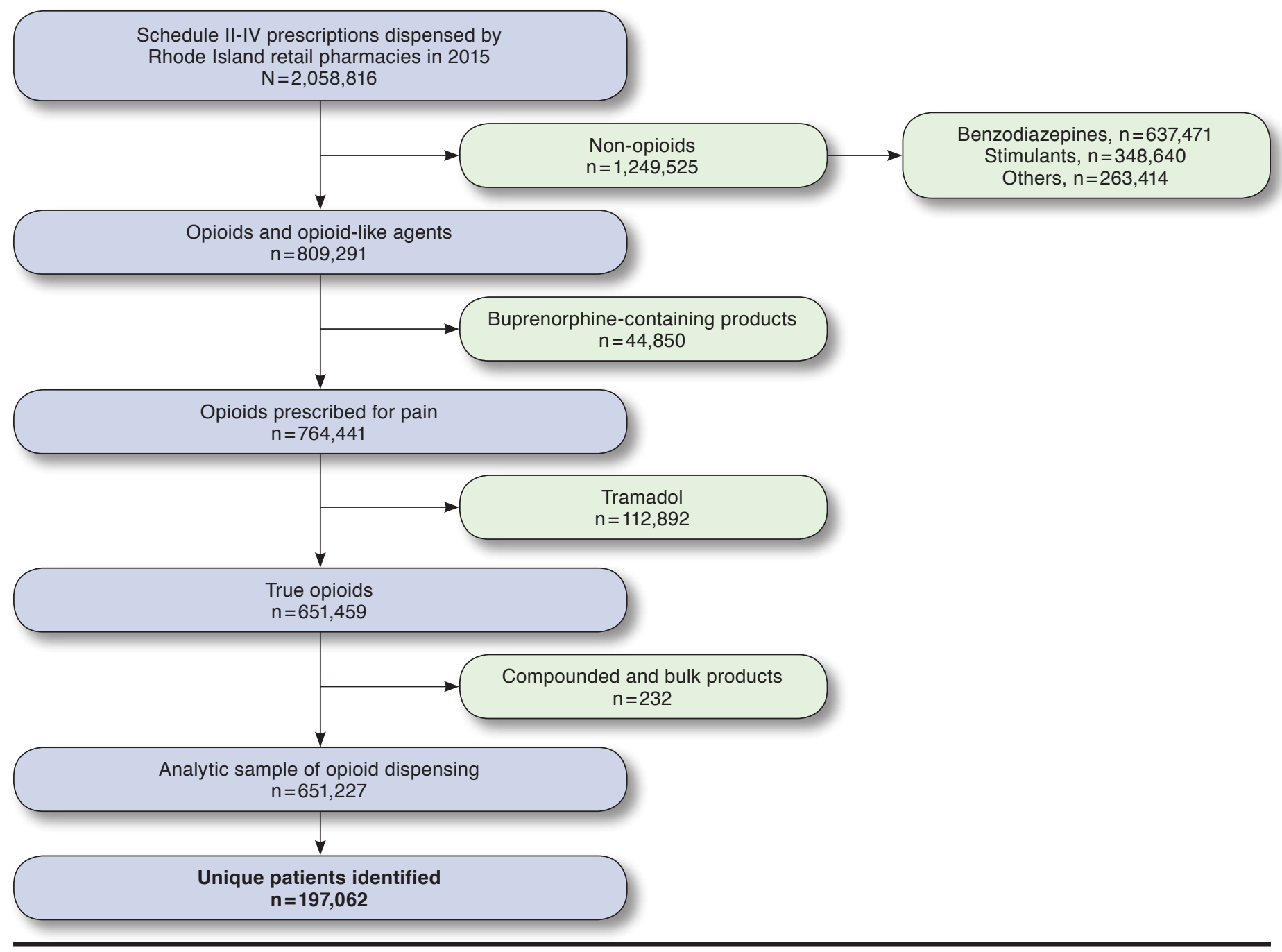

\section{Cohort Selection}

All individuals with at least 1 prescription dispensing of any Schedule II-IV controlled substance were first identified. There were 2,058,816 controlled substance prescriptions dispensed at retail pharmacies in 2015, including opioid analgesics, benzodiazepines, stimulants, skeletal muscles relaxants, and sleep aids. All prescriptions for non-opioid agents were first excluded (Figure 1); buprenorphine-containing products were excluded, since they are typically indicated for substance and opioid use disorder treatment; tramadol was also excluded because it is considered a mixed opioid-like analgesic ${ }^{32,33}$; and compounded formulations and bulk containers for which standardized pricing benchmarks were unavailable were excluded. Opioid medications were classified by drug type using NDC numbers. The analytic sample consisted of 651,227 opioid prescriptions dispensed to 197,062 patients from retail pharmacies in Rhode Island between January 1, 2015, and December 31, 2015. The U.S. Census Bureau estimated the population of Rhode Island to be $1,056,298$ in $2015 .^{34}$ An opioid prescription dispensing was defined as any prescription drug filled at a retail pharmacy and sold to a patient or patient's agent on a particular day, whether a new or refilled prescription.

To determine the unit price of each opioid prescription, NDC numbers for opioid dispensings were first matched with the 2015 Rhode Island Medicaid Maximum Allowable Cost (MAC) listing as the default unit price for branded and generic products. For sole source (i.e., branded) products and other NDC numbers that did not match the Medicaid MAC listing, pricing data from RED BOOK Online (Truven Health Analytics, Ann Arbor, MI) was used, which provided the 
average wholesale price (AWP) and federal upper limit (FUL) prices during 2015. These costs were assigned using the lesser of AWP-14\% or FUL. The discounting of AWP was determined in consultation with experts in the field as a conservative estimate of drug costs. Sources of payment reported included cash (private pay), commercial insurance, Medicare, Medicaid, and other (i.e., worker's compensation, Indian Health Service, the Veterans Health Administration, Tricare, and other federal sources).

We hypothesized that the total annual expenditure for opioid prescriptions was associated with the use of benzodiazepines or stimulants, use of higher daily doses of opioids, and use of multiple providers and pharmacies. This study determined if opioid prescription expenditure was associated with patient age groups, gender, or payment type. Use of benzodiazepines or stimulants was defined as the use of 1 or more prescriptions of either a benzodiazepine or a stimulant within the study year. The dosage of each prescription opioid dispensed was converted to its morphine milligram equivalent (MME) per day using NDC-based conversion factors published by the Centers for Disease Control and Prevention's National Center for Injury Prevention and Control in June 2015. ${ }^{35-38}$ Less than $1 \%$ of opioid prescriptions did not have enough information to calculate the daily MME. Finally, a measure of potential health system abuse was defined as patients who received prescriptions for opioids from 5 or more prescribers and filled by 5 or more pharmacies within the 12-month period (called 5/5/12 criteria)—referred to as multiple provider episodes (MPE) or "doctor shopping." 39

\section{Statistical Analysis}

The mean, median, and total costs of opioid use were estimated using opioid prescription dispensings and patients as units of analysis. All costs were retained in 2015 U.S. dollars. The last opioid prescription received during the study year was used to identify the most recently used opioid type and and to assign medication type and source of payment when patients were used as the unit of analysis. We determined overall annual spending for opioid medications and further categorized spending by age group (aged $<18,18-24,25-34,35-44,45-54$, 55-64, and 65+ years); gender; medication type; and payment type. Annual cost values were non-normally distributed with a large right skew (skewness $=22.66$ ).

With patients as the unit of analysis, a generalized linear model with gamma distribution with an identity link function, and separately with a log link function, was used to estimate the absolute and relative differences in per-patient annual adjusted average prescription opioid cost, respectively, by potential predictors. ${ }^{40,41}$ Independent variables included in the model were age group, gender, payment type, mean daily MME per patient, use of benzodiazepines or stimulants, and MPE. The modified Park test was used to identify and specify the appropriate distribution of the dependent variable

\begin{tabular}{|c|c|c|}
\hline TABLE 1 & \multicolumn{2}{|c|}{$\begin{array}{l}\text { Characteristics of Patients with at Least } 1 \\
\text { Opioid Prescription Fill at a Rhode Island } \\
\text { Retail Pharmacy in } 2015 \text { (N=197,062) }\end{array}$} \\
\hline haracteristic ${ }^{a}$ & \multicolumn{2}{|c|}{ n (\%) } \\
\hline nder $^{b}$ & & \\
\hline Female & 110,001 & $(55.82)$ \\
\hline Male & 87,043 & $(44.17)$ \\
\hline \multicolumn{3}{|l|}{ ge group, years } \\
\hline 18 & 5,995 & $(3.04)$ \\
\hline $8-24$ & 15,327 & $(7.78)$ \\
\hline $5-34$ & 27,302 & $(13.85)$ \\
\hline $5-44$ & 27,738 & $(14.08)$ \\
\hline $5-54$ & 37,155 & $(18.85)$ \\
\hline $55-64$ & 38,372 & $(19.47)$ \\
\hline 65 & 45,173 & $(22.92)$ \\
\hline
\end{tabular}

\begin{tabular}{|c|c|c|}
\hline \multicolumn{3}{|l|}{ Payment method } \\
\hline Commercial insurance & 114,654 & $(58.18)$ \\
\hline Medicare & 43,213 & $(21.93)$ \\
\hline Cash & 19,476 & $(9.88)$ \\
\hline Medicaid & 15,767 & $(8.00)$ \\
\hline Otherc & 3,952 & $(2.01)$ \\
\hline \multicolumn{3}{|c|}{ Most recent opioid dispensed } \\
\hline Hydrocodone & 90,151 & $(45.75)$ \\
\hline Oxycodone & 73,622 & $(37.36)$ \\
\hline Codeine base & 18,409 & $(9.34)$ \\
\hline Morphine & 6,894 & $(3.50)$ \\
\hline Hydromorphone & 3,698 & $(1.88)$ \\
\hline Fentanyl & 1,450 & $(0.74)$ \\
\hline Methadone & 650 & $(0.33)$ \\
\hline Tapentadol & 192 & $(0.10)$ \\
\hline Oxymorphone & 146 & $(0.07)$ \\
\hline Meperidine & 64 & $(0.03)$ \\
\hline Pentazocine & 50 & $(0.03)$ \\
\hline Butorphanol & 35 & $(0.02)$ \\
\hline Levorphanol & 1 & $(0.00)$ \\
\hline Othersd & 1,700 & $(0.86)$ \\
\hline \multicolumn{3}{|c|}{ Mean daily MME per patient ${ }^{\mathrm{e}}$} \\
\hline$\leq 50$ & 153,085 & $(77.68)$ \\
\hline $50-90$ & 32,081 & $(16.28)$ \\
\hline $90+$ & 8,536 & (4.33) \\
\hline \multicolumn{3}{|l|}{ Benzodiazepine use } \\
\hline No & 144,899 & $(73.53)$ \\
\hline Yes & 52,163 & $(26.47)$ \\
\hline \multicolumn{3}{|l|}{ Stimulant use } \\
\hline No & 188,343 & $(95.58)$ \\
\hline Yes & 8,719 & $(4.42)$ \\
\hline \multicolumn{3}{|l|}{ 5/5/12 criteria $^{f}$} \\
\hline Not met & 196,653 & (99.79) \\
\hline Met & 409 & $(0.21)$ \\
\hline
\end{tabular}

${ }^{a}$ Gender, payment method, medication type, and mean daily MME classified according to data captured in the last opioid prescription dispensed in 2015. ${ }^{b}$ Gender was not reported for 18 patients $(0.01 \%)$.

'Includes worker's compensation, Indian Health Services, Veterans Health Administration, Tricare, and other federal sources.

dPrimarily opioid-containing cough products (see Appendix B, available in online article).

eUnable to determine MME for 3,360 (1.71\%) patients.

f5/5/12/ criteria: opioid prescriptions from at least 5 different pharmacies and 5 different prescribers during the 12-month period.

$M M E=$ morphine milligram equivalent . 
conditional on the link function. The gamma family was selected, which has a constant coefficient of variation and assumes that the variance is proportional to the square of the mean. ${ }^{41,42}$ All analyses were performed with SAS version 9.4 (SAS Institute, Cary, NC), and all statistical tests were 2-sided and performed at the 0.05 significance level. This study was approved by the institutional review board at the University of Rhode Island.

\section{Results}

The study population consisted of 197,062 patients who filled a total of 651,227 opioid prescriptions in 2015. This number represents an estimated $18.7 \%$ of patients in Rhode Island who received at least 1 dispensing for an opioid medication from a retail pharmacy during 2015. Approximately 56\% of patients who filled at least 1 opioid prescription were female (Table 1). About 23.9\% of patients were aged 65 years and older, and $38.3 \%$ were aged $45-64$ years. Based on the last opioid prescription dispensed, most patients were prescribed either hydrocodone or oxycodone (83.1\%). Approximately $58.2 \%$ of patients had commercial insurance; $21.9 \%$ were covered by Medicare; and almost $10 \%$ of patients paid for their prescriptions using cash. More than $90 \%$ of patients used only 1 method of payment during the study year. A subgroup analysis of cash payment for all opioid prescriptions showed that 21,538 patients used cash payment for least 1 opioid prescription in 2015. Among them, 16,240 (75.40\%) patients used only cash payment for all opioid prescriptions filled at the retail pharmacy, while $5,298(24.60 \%)$ patients used 2 or more types of insurance payment during the same calendar year (Appendix A, available in online article).

The total 2015 annual retail expenditure for opioid prescriptions in Rhode Island was estimated at $\$ 44,271,827$, which corresponded to an average spending of $\$ 3.7$ million per month. The average and median costs of an opioid prescription were \$67.98 (standard deviation [SD] \$210.91) and \$21.08 (quartile 1 to quartile 3 [Q1-Q3]=\$7.65-\$47.51), respectively. Both the number of opioid prescriptions dispensed and perpatient annual spending increased with age but appeared to stabilize among patients aged 45 years or older (Table 2). The total annual prescription opioid spending for patients aged 45-64 years was estimated to be $\$ 26,337,403.49$, which was not only proportionately higher compared with patients aged 65 years and older but also higher than spending for any other age group.

Oxycodone and hydrocodone were the most commonly dispensed opioid prescriptions, accounting for more than $82 \%$ of all prescriptions filled. The total annual expenditure for these 2 drug types was approximately $\$ 32.5$ million, which accounted for $73 \%$ of all opioid prescription spending. The average cost of an oxycodone prescription was approximately $\$ 50$ more than hydrocodone, reflecting a dramatically higher cost for extended-release oxycodone compared with hydrocodone products, which were mostly dispensed in generic immediaterelease forms. The average and median costs of a prescription of oxymorphone were $\$ 595.72$ (SD \$512.60) and $\$ 439.68$ (Q1-Q3 = \$246.94-\$779.81), respectively, making it the most costly opioid prescription type among branded and generic products.

Branded opioid prescriptions were far more expensive than their generic counterparts. However, 94\% of all opioid prescriptions were for a generic product, with an average price of $\$ 43.90$ (SD \$116.21) compared with \$449.78 (SD \$616.97) per branded prescription. Branded opioid prescriptions accounted for $\$ 17,380,279.05$ of the yearly total, which was about $39.3 \%$ of overall spending, although only $6 \%$ of all opioids dispensed were for branded drugs.

Commercial insurance was the most common method of payment type for opioid prescriptions (51\%), followed by Medicare (29.4\%). Cash payment was used for 60,548 (9.3\%) of all prescription opioids dispensed. We found that, on average, Medicare spent $\$ 85.31$ (95\% confidence interval $[\mathrm{CI}]=\$ 84.24$ $\$ 86.39)$ per opioid prescription, which was significantly more than Medicaid and private insurance, which spent $\$ 52.15$ (95\% $\mathrm{CI}=\$ 50.82-\$ 53.48)$ and $\$ 65.55(95 \% \mathrm{CI}=\$ 64.83-\$ 66.28)$ per prescription, respectively. However, commercial insurance was responsible for $49.3 \%$ of the total expenditure, while Medicaid and Medicare paid for only $6.1 \%$ and $36.9 \%$, respectively. Cash payment represented $5.1 \%$ of the annual spending.

Table 3 presents the results of a generalized linear model. Using a gamma regression model with an identity link function, gender, age group, payment type, mean daily MME per patient, use of benzodiazepines or stimulants, and MPE were statistically significant predictors of total annual expenditure. Patients aged 45-54 years and 55-64 years had overall adjusted mean spending for opioids that was $\$ 17.65$ (95\% CI $=\$ 15.26$ $\$ 20.04)$ and $\$ 28.47$ (95\% CI $=\$ 26.06-\$ 30.88)$ higher, respectively, than patients aged 65 years and older. As expected, the youngest patients had significantly lower adjusted total expenditure per patient compared with adults aged over 65 years. With regard to method of payment, overall adjusted mean costs per Medicare and Medicaid patients were $\$ 33.20$ $(95 \% \mathrm{CI}=\$ 31.05-\$ 35.35)$ and $\$ 0.56(95 \% \mathrm{CI}=-\$ 0.51-\$ 1.63)$ higher, respectively, compared with commercially insured patients, while patients who used cash payments spent on average $\$ 3.80$ less than the amount charged to customers with commercial insurance.

Patients who were dispensed benzodiazepines (26.5\%) or sympathomimetic stimulants (4.4\%) had higher annual spending for opioid medications than those who did not receive these medications. On average, adjusted annual opioid prescription cost was $\$ 35.99$ (95\% CI $=\$ 34.45-\$ 37.54$ ) higher among patients who also received at least 1 benzodiazepine dispensing, while adjusted annual opioid prescription cost was $\$ 8.61$ (95\% CI $=\$ 6.47-\$ 10.76)$ higher among patients who 
Estimating the Direct Costs of Outpatient Opioid Prescriptions: A Retrospective Analysis of Data from the Rhode Island Prescription Drug Monitoring Program

TABLE 2 Opioid Prescriptions Dispensed by Rhode Island Retail Pharmacies in 2015

\begin{tabular}{|c|c|c|c|c|c|}
\hline \multirow[b]{2}{*}{ Characteristic } & \multirow{2}{*}{$\begin{array}{c}\text { Number of } \\
\text { Prescriptions (\%) }\end{array}$} & \multicolumn{3}{|c|}{ Prescription Cost, $\$$} & \multirow[b]{2}{*}{$\%$ Total Cost } \\
\hline & & Mean (SD) & \multirow{2}{*}{$\begin{array}{c}\text { Median } \\
21.08\end{array}$} & \multirow{2}{*}{$\begin{array}{c}\text { Total } \\
44,271,827.00\end{array}$} & \\
\hline Overall & 651,227 & $67.98 \quad(210.91)$ & & & 100.00 \\
\hline \multicolumn{6}{|l|}{ Age group, years } \\
\hline$<18$ & $7,889 \quad(1.21)$ & (41.63) & 8.54 & $163,902.33$ & 0.37 \\
\hline $18-24$ & $22,794 \quad(3.50)$ & $15.45 \quad(43.29)$ & 7.02 & $352,063.77$ & 0.80 \\
\hline $25-34$ & $57,597 \quad(8.84)$ & $34.55 \quad(145.80)$ & 9.36 & $1,990,258.63$ & 4.50 \\
\hline $35-44$ & $84,085 \quad(12.91)$ & 61.08 (223.88) & 16.47 & $5,135,736.95$ & 11.60 \\
\hline $45-54$ & $144,608 \quad(22.21)$ & $81.01 \quad(247.86)$ & 22.95 & $11,714,458.06$ & 26.46 \\
\hline $55-64$ & $162,352 \quad(24.93)$ & $90.07 \quad(251.01)$ & 25.32 & $14,622,945.43$ & 33.03 \\
\hline$\geq 65$ & $171,902 \quad(26.40)$ & 59.87 (154.39) & 22.95 & $10,292,461.84$ & 23.25 \\
\hline \multicolumn{6}{|l|}{ Medication type } \\
\hline Butorphanol & $355 \quad(0.05)$ & $163.90 \quad(109.88)$ & 163.59 & $58,184.34$ & 0.13 \\
\hline Codeine based & $37,100 \quad(5.70)$ & $6.86 \quad(6.99)$ & 4.43 & $254,557.96$ & 0.57 \\
\hline Fentanyl & $15,169 \quad(2.33)$ & $204.43 \quad(552.01)$ & 126.66 & $3,101,069.73$ & 7.00 \\
\hline Hydrocodone & $253,850 \quad(38.98)$ & $34.15 \quad(54.21)$ & 21.42 & $8,668,532.13$ & 19.58 \\
\hline Hydromorphone & $9,717 \quad(1.47)$ & $209.70 \quad(554.09)$ & 18.23 & $2,037,677.97$ & 4.60 \\
\hline Levorphanol & $\begin{array}{ll}9 & (0.00) \\
\end{array}$ & $560.08 \quad(907.64)$ & 103.12 & $5,040.76$ & 0.01 \\
\hline Meperidine & $261 \quad(0.04)$ & $29.20 \quad(24.95)$ & 19.13 & $7,620.44$ & 0.02 \\
\hline Methadone & $7,156 \quad(1.10)$ & $41.82 \quad(32.23)$ & 29.70 & $299,254.81$ & 0.68 \\
\hline Morphine & $35,462 \quad(5.45)$ & $108.67 \quad(267.76)$ & 40.22 & $3,853,808.20$ & 8.70 \\
\hline Oxycodone & $281,225 \quad(43.18)$ & $84.69 \quad(235.80)$ & 21.18 & $23,817,051.40$ & 53.80 \\
\hline Oxymorphone & $1,810 \quad(0.28)$ & $595.72(512.60)$ & 439.68 & $1,078,255.85$ & 2.44 \\
\hline Pentazocine & $341 \quad(0.05)$ & $173.27 \quad(178.45)$ & 178.75 & $59,084.86$ & 0.13 \\
\hline Tapentadol & $1,103 \quad(0.17)$ & $492.86 \quad(293.16)$ & 421.98 & $543,626.74$ & 1.23 \\
\hline Others $^{\mathrm{a}}$ & $7,669 \quad(1.18)$ & $63.64 \quad(99.66)$ & 38.16 & $488,061.81$ & 1.10 \\
\hline \multicolumn{6}{|l|}{ MME dailyb } \\
\hline$\leq 50$ & $430,519 \quad(66.11)$ & $30.28 \quad(53.62)$ & 14.39 & $13,034,889.82$ & 29.44 \\
\hline $50-90$ & $135,105 \quad(20.75)$ & $70.26 \quad(137.46)$ & 28.51 & $9,492,612.15$ & 21.44 \\
\hline $90+$ & $81,145 \quad(12.46)$ & $265.42 \quad(513.27)$ & 87.73 & $21,537,624.36$ & 48.65 \\
\hline \multicolumn{6}{|l|}{ Generic or brand } \\
\hline Generic & $612,585 \quad(94.07)$ & $43.90 \quad(116.21)$ & 19.13 & $26,891,547.96$ & 60.74 \\
\hline Brand & $38,642 \quad(5.93)$ & $449.78 \quad(616.97)$ & 279.43 & $17,380,279.05$ & 39.26 \\
\hline \multicolumn{6}{|l|}{ Duration of action } \\
\hline Short acting & $579,849 \quad(89.04)$ & $38.27 \quad(128.72)$ & 16.47 & $22,190,457.00$ & 50.12 \\
\hline Long acting & $71,378 \quad(10.96)$ & $309.36 \quad(453.68)$ & 136.26 & $22,081,370.01$ & 49.88 \\
\hline \multicolumn{6}{|l|}{ Payment type ${ }^{c}$} \\
\hline Commercial & $332,088 \quad(50.99)$ & $65.55 \quad(213.46)$ & 19.00 & $21,769,832.09$ & 49.17 \\
\hline Medicare & $191,554 \quad(29.41)$ & $85.31 \quad(240.12)$ & 28.08 & $16,341,749.85$ & 36.91 \\
\hline Medicaid & $51,490 \quad(7.91)$ & $52.15 \quad(154.24)$ & 15.13 & $2,685,118.58$ & 6.07 \\
\hline Private pay & $60,548 \quad(9.30)$ & $37.18 \quad(97.84)$ & 14.39 & $2,251,262.97$ & 5.09 \\
\hline Otherd & $15,546 \quad(2.39)$ & $78.72 \quad(234.92)$ & 20.11 & $1,223,849.24$ & 2.76 \\
\hline \multicolumn{6}{|c|}{$\begin{array}{l}\text { aPrimarily opioid-containing cough products (see Appendix B, available in online article). } \\
\text { bUnable to determine MME for } 0.68 \% \text { of observations. } \\
\text { 'If patient was aged } \geq 65 \text { years with commercial insurance, then payment type was reclassified as Medicare. Method of payment was missing for } 1 \text { prescription. } \\
\text { dIncludes worker's compensation, Indian Health Services, Veterans Health Administration, Tricare, and other federal sources. } \\
M M E=\text { morphine milligram equivalent; SD=standard deviation. }\end{array}$} \\
\hline
\end{tabular}

also had at least 1 dispensing for a stimulant medication. As a statistically significant predictor of annual opioid expenditure, for patients with MPE, average adjusted annual cost of opioid prescriptions per patient was increased by approximately $\$ 863.58$ (95\% CI $=\$ 689.48-\$ 1,037.68)$ compared with patients who did not meet this criteria. The adjusted annual total opioid spending per patient also increased substantially with the use of higher daily doses of opioids, since average total cost was more than $\$ 337.73$ (95\% CI $=\$ 332.84-\$ 342.62)$ greater among patients using on average more than $90 \mathrm{MME}$ daily, compared with patients receiving on average of less than 50 MME daily. 


\begin{tabular}{|c|c|c|c|c|}
\hline Independent Variable & $\begin{array}{c}\text { Mean Cost Difference, } \$ \text { a } \\
(95 \% \mathrm{CI})\end{array}$ & Adjusted $\beta$ coefficient $^{\mathrm{b}}$ & Standard Error & $95 \% \mathrm{CI}$ \\
\hline Intercept & $64.17 \quad(62.25,66.10)$ & 3.8415 & 0.0136 & $(3.8149,3.8680)$ \\
\hline \multicolumn{5}{|l|}{ Age group (years) } \\
\hline $65+$ & Reference & & & \\
\hline$<18$ & $-45.89(-48.09,-43.68)$ & -1.1680 & 0.0243 & $(-1.2157,-1.1204)$ \\
\hline $18-24$ & $-50.22(-52.13,-48.31)$ & -1.2910 & 0.0173 & $(-1.3250,-1.2571)$ \\
\hline $25-34$ & $-42.10 \quad(-44.04,-40.17)$ & -0.7492 & 0.0150 & $(-0.7786,-0.7198)$ \\
\hline $35-44$ & $-11.89 \quad(-14.20,-9.59)$ & -0.0415 & 0.0149 & $(-0.0706,-0.0124)$ \\
\hline $45-54$ & $17.65 \quad(15.26,20.04)$ & 0.4257 & 0.0139 & $(0.3985,0.4530)$ \\
\hline $55-64$ & $28.47 \quad(26.06,30.88)$ & 0.5621 & 0.0137 & $(0.5353,0.5888)$ \\
\hline \multicolumn{5}{|l|}{ Gender } \\
\hline Female & Reference & & & \\
\hline Male & $(4.44,5.84)$ & 0.1364 & 0.0070 & $(0.1228,0.1501)$ \\
\hline \multicolumn{5}{|l|}{ Payment type ${ }^{c}$} \\
\hline Commercial & Reference & & & \\
\hline Medicaid & $0.56 \quad(-0.51,1.63)$ & 0.1733 & 0.0129 & $(0.1481,0.1986)$ \\
\hline Medicare & $33.20 \quad(31.05,35.35)$ & 0.6971 & 0.0127 & $(0.6722,0.7220)$ \\
\hline Private pay & $-3.80 \quad(-4.69,-2.91)$ & -0.1917 & 0.0129 & $(-0.2170,-0.1663)$ \\
\hline Otherd & $9.16 \quad(5.17,13.15)$ & 0.2988 & 0.0250 & $(0.2498,0.3479)$ \\
\hline \multicolumn{5}{|c|}{ Mean daily MME per patient } \\
\hline$\leq 50$ & Reference & & & \\
\hline $50-90$ & $97.91 \quad(95.14,100.68)$ & 1.0756 & 0.0092 & $(1.0575,1.0938)$ \\
\hline$>90$ & $337.73(332.84,342.62)$ & 3.1124 & 0.0168 & $(3.0795,3.1453)$ \\
\hline \multicolumn{5}{|l|}{ Benzodiazepine use ${ }^{e}$} \\
\hline No & Reference & & & \\
\hline Yes $(n=52,163)$ & $35.99 \quad(34.45,37.54)$ & 0.6980 & 0.0079 & $(0.6825,0.7135)$ \\
\hline \multicolumn{5}{|l|}{ Stimulant use $e^{e}$} \\
\hline No & Reference & & & \\
\hline Yes $(n=8,719)$ & $(6.47,10.76)$ & 0.4062 & 0.0167 & $(0.3735,0.4390)$ \\
\hline \multicolumn{5}{|l|}{$5 / 5 / 12$ criteriaf $^{f}$} \\
\hline Not met & Reference & & & \\
\hline Met $(n=409)$ & $863.58(689.48,037.68)$ & 1.4672 & 0.0741 & $(1.3220,1.6125)$ \\
\hline \multicolumn{5}{|c|}{ 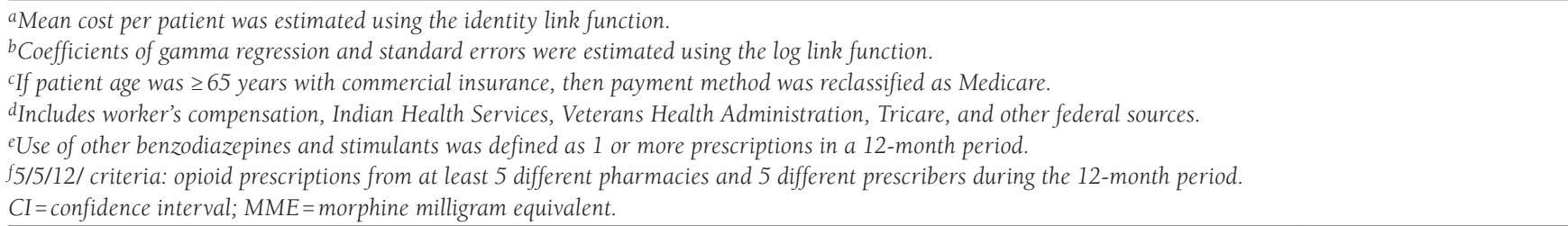 } \\
\hline
\end{tabular}

Using a gamma regression model with a log link function (Table 3), there was a 69\% reduction in overall adjusted average cost per patient when comparing those who were aged 18 years or younger to those aged 65 years and older. Conversely, patients aged 45-54 years and 55-64 years had overall adjusted average spending for opioids that were 1.53 (95\% CI=1.49$1.57)$ and 1.75 (95\% CI=1.71-1.80) times higher, respectively, than patients aged 65 years and older. Per patient Medicaid and Medicare average adjusted annual spending for opioid prescriptions were 1.19 (95\% CI $=1.16-1.22)$ and 2.01 (95\% CI $=1.96$ 2.06) times higher than commercial insurance spending, respectively, while average spending per patient using cash payment was $17.4 \%$ lower than charges to commercial payers.

Patients who were dispensed benzodiazepines or a sympathomimetic stimulants had higher annual spending for opioid medications than those who were not. On average, adjusted annual opioid prescription spending was 2.01 (95\% CI $=1.98$ 2.04) and 1.50 (95\% CI=1.45-1.55) times higher among patients who also had at least 1 benzodiazepine or stimulant dispensing, respectively. Average adjusted total spending for prescription opioids per patient increased with the average daily dosage: from 3-fold for patients using 50-90 MME daily 
to 22-fold for those receiving 90 or more MME daily compared with those receiving less than 50 MME daily. Patients with MPEs had mean adjusted annual opioid spending that was 4.34 (95\% CI $=3.75-5.02)$ times higher than patients who did not use multiple prescribers and pharmacies.

\section{Discussion}

In 2015, 197,062 patients (an estimated 18.7\% of the state's population) received at least 1 dispensing for an opioid medication from a retail pharmacy in Rhode Island. The total number of opioid prescriptions filled was 651,227, which corresponds to an average of 3.3 prescriptions per resident per year, or an estimated opioid prescribing rate of 61.65 prescriptions per 100 residents. This rate is comparable to rates estimated for other neighboring states and the rest of the country. ${ }^{39,43}$

The direct cost burden of prescription opioids was determined using data from a statewide PDMP, capturing controlled substance dispensings at the pharmacy level and encompassed dispensings for all providers and payment types, including cash. Thus, estimates from this study provide results that are more generalizable to the overall population, compared with analyses of a particular payer's pharmacy claims. Because PDMP programs do not include drug pricing information, this information was assimilated from other sources, providing what we believe is the first estimate of the direct annual cost burden of prescription opioid use, estimated at $\$ 44,271,827.00$ for a population of approximately 1 million, in 2015 U.S. dollars. This estimate represents about $3.7 \%$ of total prescription drug sales at retail pharmacies in Rhode Island for 2016, according to a report published recently by the Kaiser Family Foundation (2017) ${ }^{44}$ According to this report, which was based on IMS Health national prescription audit data, the total 2016 expenditure for all 18 million prescription drugs dispensed at retail pharmacies in Rhode Island was estimated at $\$ 1.2$ billion. The estimate from our study does not include dispensings for tramadol, compounded products, or opioids dispensed in substance and opioid use disorder treatment centers, during inpatient hospital care, or in state correctional facilities.

In our study, the cost associated with prescription opioid use was determined in part by the intensity of use (i.e., number of dispensings and daily dosage) and the opioid product prescribed. Patients aged 45-64 years accounted for 47.14\% of all opioid prescriptions dispensed and $59.49 \%$ of the total expenditure. While mean costs were highest for prescriptions for oxymorphone (\$595.72), levorphanol (\$560.80), and tapentadol (\$492.86), dispensings for these medications accounted for only $3.7 \%$ of total overall annual cost. More than half (53.8\%) of the annual cost of opioid medications for 2015 was associated with oxycodone dispensings, most of which can be attributed to higher-cost extended-release formulations, which accounted for almost $50 \%$ of the total annual expenditure even though they represented only $11 \%$ of all prescriptions. Efforts to address the cost burden of opioid overuse might target this middle-aged subgroup, with a focus on reducing the long-term use of opioids, many of which are prescribed as higher-cost extended-release formulations. Evidence for the use of opioids for chronic pain is limited amidst mounting evidence of serious dose-dependent harm..$^{45}$ Decreasing the unnecessary use of extended-release oxycodone for treatment of acute pain and the availability of a less costly generic formulation of this medication would have a dramatic effect on opioid expenditure, potentially yielding significant savings to the health care system.

Doctor-shopping behavior and the use of cash for prescription opioid payment, especially when the patient also has other types of insurance coverage, may indicate prescription opioid misuse. ${ }^{46}$ About 21,538 (10.93\%) patients paid for at least 1 opioid prescription with cash during the 2015 calendar year, and approximately $25 \%$ of these patients used at least 1 other type of insurance to pay for opioid prescriptions during the same year. The overall adjusted average prescription opioid spending by the 409 patients who met the 5/5/12 criteria was dramatically greater than that spent by patients who did not meet these criteria ( $\$ 64.17$ vs. $\$ 927.76, P<0.001$ ). However, higher costs associated with potential doctor shopping or use of benzodiazepines or stimulants may be an indication of poorly managed comorbid chronic conditions resulting from lack of coordinated care.

Other valid reasons for having multiple providers might include a change in primary care providers, different providers covering a patient's usual prescriber, having multiple specialists, and visits to dentists or the emergency room. ${ }^{47}$ It is envisioned that the overuse of prescribers and pharmacies will decrease with increasing public awareness and implementation of regulations that require providers to review the PDMP before issuing a prescription for an opioid medication. However, most PDMPs are not currently integrated with electronic medical records, which makes access to this information time consuming and often unfeasible.

The finding in this study that nearly 1 in 5 state residents received at least 1 opioid prescription during 2015 indicates that opioids are commonly prescribed within the state and suggests that a proportion of opioid prescribing may be clinically unnecessary. Levy et al. (2015) reported that opioids are the most commonly prescribed analgesics in the United States. ${ }^{48}$ This study, however, did not examine the clinical indications for which these opioid prescriptions were dispensed, so we could not quantify the extent and cost of inappropriate opioid prescribing. Liu et al. (2013), on the other hand, found that up to $40 \%$ of Medicaid patients receiving an opioid prescription had at least 1 marker of inappropriate prescribing, such as overlapping opioid prescriptions, overlapping opioid and benzodiazepine prescriptions, initiation of therapy with a 
long-acting opioid, use of long-acting opioids for acute pain, or high daily doses more than 90 MME. ${ }^{24}$

The Centers for Disease Control and Prevention recently published guidelines for prescribing opioids for chronic pain in the absence of cancer, palliative, or terminal care. ${ }^{19}$ These guidelines recommend the use of non-opioids as first-line therapy for chronic pain, using opioid analgesics only when the benefits of such therapy are likely to outweigh the risks and prescribing the lowest effective dosage for the shortest number of days, when needed. Many insurers have introduced new policies to reduce inappropriate opioid prescribing, such as drug utilization review, prior authorization, quantity limitations, and pharmacy management review programs. ${ }^{49,50}$ Trends in opioid prescribing should continue to be monitored as a measure of effectiveness of current public health interventions and narcotic stewardship programs, in order to determine if the frequency and cost burden of opioid use is diminishing.

\section{Limitations}

This study has some limitations to consider. The PDMP database does not include information describing health conditions or patient diagnoses, laboratory tests, clinician specialty, use of noncontrolled prescription medications, or any other indicators of health care utilization. Since the analysis could not determine whether an opioid prescription was appropriate, we could not quantify the cost of inappropriate opioid prescribing, which limited the application of these results to improve prescribing practices.

The total cost estimate does not represent the total cost burden, since we could not estimate the cost of adverse effects or account for opioid prescriptions not filled in retail pharmacies. Furthermore, estimates from this study are a general approximation because payer reimbursement rates may vary from the methods we applied in our analysis to some degree. Also, a patient's state of residence could not be determined. However, the number of patients from neighboring states who received opioid prescriptions from Rhode Island pharmacies is likely to be offset by the number of Rhode Island residents who filled opioid prescriptions at pharmacies in neighboring states.

The payment type variable was poorly reliable with regard to capturing Medicare as a payment source. An undetermined number of older adults were misclassified as having commercial insurance, and while we attempted to address this issue by reassigning these patients as covered by a Medicare drug plan, our ability to make inferences regarding opioid expenditure, by Medicare Advantage plans in particular, was nevertheless limited.

Finally, we recognize that the direct cost of prescriptions is merely 1 component driving health system expenses associated with pain management and opioid use in particular. Consideration of other treatment modalities, medical care, and humanistic outcomes should be included in health economic analyses that assess opioid use as facet of pain management.

\section{Conclusions}

This study provides the first estimate of a statewide direct cost burden of prescription opioid use using PDMP data and standardized pricing benchmarks. Total annual cost increased with age up to 65 years, mean daily dose, and concurrent use of benzodiazepines or stimulants. Commercial insurance bore the majority of the cost of prescription opioid use, but cost per patient was highest among Medicare beneficiaries. Almost 11\% of patients used cash payment at least once during the 2015 calendar year, and cash payment accounted for about $5.1 \%$ of the total annual prescription opioid expenditure.

This analysis suggests that substantial cost savings could result from increased use of generic formulations of commonly prescribed opioid products. Greater savings and improved patient health outcomes could be realized by reducing overall opioid use, especially among middle-aged individuals.

\section{Authors}

HILARY AROKE, MD, MPH; ASHLEY BUCHANAN, DrPH, MS; XUERONG WEN, PhD, MS; and STEPHEN KOGUT, PhD, MBA, RPh, Program in Health Outcomes Research, Department of Pharmacy Practice, University of Rhode Island College of Pharmacy, Kingston. PETER RAGOSTA, RPh, and JENNIFER KOZIOL, MPH, Rhode Island Department of Health, Providence.

AUTHOR CORRESPONDENCE: Hilary Aroke, MD, MPH, Department of Pharmacy Practice, University of Rhode Island College of Pharmacy, 7 Greenhouse Rd., Rm. 265, Kingston, RI 02881. Tel.: 401.874.5370; E-mail: aharoke@gmail.com.

\section{DISCLOSURES}

This study was funded by the Rhode Island Department of Health. Aroke and Kogut report grants from the Rhode Island Department of Health during this study. Kogut is partially supported by Institutional Development Award Number U54GM115677 from the National Institute of General Medical Sciences of the National Institutes of Health, which funds Advance Clinical and Translational Research (Advance-CTR). Koziol reports grants from the Centers for Disease Control and Prevention during this study. The other authors have nothing to disclose. The content of this study is solely the responsibility of the authors and does not necessarily represent the official views of the National Institutes of Health.

Study concept and design were contributed by Koziol, Ragosta, and Kogut, along with Aroke. Koziol, Ragosta, Aroke, and Kogut collected the data, and data interpretation was performed by Aroke, Buchanan, Wen, and Kogut. The manuscript was primarily written by Aroke, along with Buchanan and Kogut, and revised by Aroke, Buchanan, Wen, and Kogut.

\section{REFERENCES}

1. Watkins EA, Wollan PC, Melton LJ 3rd, Yawn BP. A population in pain: report from the Olmsted County health study. Pain Med. 2008;9(2):166-74.

2. Elliott AM, Smith BH, Penny KI, Smith WC, Chambers WA. The epidemiology of chronic pain in the community. Lancet. 1999;354(9186):1248-52. 


\section{Estimating the Direct Costs of Outpatient Opioid Prescriptions: A Retrospective Analysis of Data from the Rhode Island Prescription Drug Monitoring Program}

3. Gureje O, Von Korff M, Simon GE, Gater R. Persistent pain and wellbeing: a World Health Organization Study in primary care. JAMA. 1998;280(2):147-51.

4. Institute of Medicine. Relieving Pain in America: A Blueprint for Transforming Prevention, Care, Education, and Research. Washington, DC: The National Academies Press; 2011

5. Paulozzi LJ, Mack KA, Hockenberry JM. Vital signs: variation among states in prescribing of opioid pain relievers and benzodiazepines - United States, 2012. MMWR Morb Mortal Wkly Rep. 2014;63(26):563-68.

6. Portenoy RK. Opioid therapy for chronic nonmalignant pain: a review of the critical issues. J Pain Symptom Manage. 1996;11(4):203-17.

7. Joranson DE, Ryan KM, Gilson AM, Dahl JL. Trends in medical use and abuse of opioid analgesics. JAMA. 2000;283(13):1710-14.

8. Berry PH, Dahl JL. The new JCAHO pain standards: implications for pain management nurses. Pain Manag Nurs. 2000;1(1):3-12.

9. Manning WG, Newhouse JP, Duan N, Keeler EB, Leibowitz A, Marquis MS. Health insurance and the demand for medical care: evidence from a randomized experiment. Am Econ Rev. 1987;77(3):251-77.

10. Alpert A, Lakdawalla D, Sood N. Prescription drug advertising and drug utilization: the role of Medicare Part D. NBER Working Paper 21714. National Bureau of Economic Research. November 2015. Available at: http:// www.nber.org/papers/w21714. Accessed February 11, 2018

11. Centers for Disease Control and Prevention. Vital signs: overdoses of prescription opioid pain relievers - United States, 1999-2008. MMWR Morb Mortal Wkly Rep. 2011;60(43):1487-92.

12. Paulozzi LJ. Prescription drug overdoses: a review. J Safety Res. 2012;43(4):283-89.

13. Okie S. A flood of opioids, a rising tide of deaths. New Engl J Med. 2010;363(21):1981-85.

14. Chen LH, Hedegaard H, Warner M. Drug-poisoning deaths involving opioid analgesics: United States, 1999-2011. NCHS Data Brief. 2014;(166):1-8

15. Rudd RA, Seth P, David F, Scholl L. Increases in drug and opioidinvolved overdose deaths - United States, 2010-2015. MMWR Morb Mortal Wkly Rep. 2016;65(5051):1445-52.

16. Jann M, Kennedy WK, Lopez G. Benzodiazepines: a major component in unintentional prescription drug overdoses with opioid analgesics. J Pharm Pract. 2014:27(1):5-16.

17. Jones JD, Mogali S, Comer SD. Polydrug abuse: a review of opioid and benzodiazepine combination use. Drug Alcohol Depend. 2012;125(1-2):8-18.

18. Overdyk FJ, Dowling O, Marino J, et al. Association of opioids and sedatives with increased risk of in-hospital cardiopulmonary arrest from an administrative database. PloS One. 2016;11(2):e0150214.

19. Dowell D, Haegerich TM, Chou R. CDC guideline for prescribing opioids for chronic pain-United States, 2016. MMWR Recomm Rep. 2016;65(1):1-49.

20. U.S. Food and Administration. FDA drug safety communication: FDA warns about serious risks and death when combining opioid pain or cough medicines with benzodiazepines; requires its strongest warning. Safety announcement. August 31, 2016. Available at: https://www.fda.gov/Drugs/ DrugSafety/ucm518473.htm. Accessed February 11, 2018.

21. Calcaterra S, Glanz J, Binswanger IA. National trends in pharmaceutical opioid related overdose deaths compared to other substance related overdose deaths: 1999-2009. Drug Alcohol Depend. 2013;131(3):263-70.

22. Deyo RA, Irvine JM, Millet LM, et al. Measures such as interstate cooperation would improve the efficacy of programs to track controlled drug prescriptions. Health Aff (Millwood). 2013;32(3):603-13.

23. Kuo YF, Raji MA, Chen NW, Hasan H, Goodwin JS. Trends in opioid prescriptions among Part D Medicare recipients from 2007 to 2012. Am J Med. 2016;129(2):221.e21-221.e30.
24. Liu Y, Logan JE, Paulozzi LJ, Zhang K, Jones CM. Potential misuse and inappropriate prescription practices involving opioid analgesics. Am J Manag Care. 2013;19(8):648-65

25. Mack KA, Zhang K, Paulozzi L, Jones C. Prescription practices involving opioid analgesics among Americans with Medicaid, 2010. J Health Care Poor Underserved. 2015;26(1):182-98.

26. White AG, Birnbaum HG, Mareva MN, et al. Direct costs of opioid abuse in an insured population in the United States. J Manag Care Pharm. 2005;11(6):469-79. Available at: https://www.jmcp.org/doi/abs/10.18553/ jmcp.2005.11.6.469.

27. Zhou C, Florence CS, Dowell D. Payments for opioids shifted substantially to public and private insurers while consumer spending declined, 1999-2012. Health Aff (Millwood). 2016;35(5):824-31.

28. Stagnitti, MN. Trends in prescribed outpatient opioid use and expenses in the U.S. civilian noninstitutionalized population, 2002-2012. Statistical Brief \#478. Agency for Healthcare Research and Quality. August 2015. Available at: https://meps.ahrq.gov/data_files/publications/st478/stat478. shtml. Accessed February 11, 2018.

29. Califf RM, Woodcock J, Ostroff S. A proactive response to prescription opioid abuse. New Engl J Med. 2016;374(15):1480-85.

30. Campbell KM, Deck D, Krupski A. Record linkage software in the public domain: a comparison of Link Plus, The Link King, and a 'basic' deterministic algorithm. Health Informatics J. 2008;14(1):5-15.

31. Beil H, Preisser JS, Rozier RG. Accuracy of record linkage software in merging dental administrative data sets. J Public Health Dent. 2013;73(2):89-93.

32. Raffa RB, Friderichs E, Reimann W, Shank RP, Codd EE, Vaught JL. Opioid and nonopioid components independently contribute to the mechanism of action of tramadol, an 'atypical' opioid analgesic. J Pharmacol Exp Ther. 1992;260(1):275-85.

33. Leppert W. Tramadol as an analgesic for mild to moderate cancer pain. Pharmacol Rep. 2009;61(6):978-92.

34. U.S. Census Bureau. QuickFacts. Rhode Island. 2015. Available at: https://www.census.gov/quickfacts/table/PST045216/44,00. Accessed February 11, 2018.

35. Von Korff M, Saunders K, Ray GT, et al. Defacto long-term opioid therapy for non-cancer pain. Clin J Pain. 2008;24(6):521-27.

36. McPherson M. Demystifying Opioid Conversion Calculations: A Guide for Effective Dosing. Bethesda, MD: American Society of Health-System Pharmacists; 2009.

37. Nielsen S, Degenhardt L, Hoban B, Gisev N. A synthesis of oral morphine equivalents (OME) for opioid utilisation studies. Pharmacoepidemiol Drug Saf. 2016;25(6):733-37.

38. Centers for Disease Control and Prevention, National Center for Injury Prevention and Control. Data resources. Analyzing prescription data and Morphine Milligram Equivalents (MME). 2016 version. Available at: https:// www.cdc.gov/drugoverdose/resources/data.html. Accessed February 20, 2018.

39. Paulozzi LJ, Strickler GK, Kreiner PW, Koris CM; Centers for Disease Control and Prevention. Controlled substance prescribing patterns-prescription behavior surveillance system, eight states, 2013. MMWR Surveill Summ. 2015;64(9):1-14.

40. Barber J, Thompson S. Multiple regression of cost data: use of generalised linear models. J Health Serv Res Policy. 2004;9(4):197-204.

41. Glick HA, Doshi JA, Sonnad SS, Polsky D. Economic Evaluation in Clinical Trials. Oxford: Oxford University Press; 2014.

42. Manning WG, Mullahy J. Estimating log models: to transform or not to transform? J Health Econ. 2001;20(4):461-94.

43. Centers for Disease Control and Prevention. U.S. state prescribing rates, 2015. Available at: https://www.cdc.gov/drugoverdose/maps/rxstate2015.

html. Accessed February 11, 2018. 


\section{Estimating the Direct Costs of Outpatient Opioid Prescriptions: A Retrospective Analysis of Data from the Rhode Island Prescription Drug Monitoring Program}

44. Kaiser Family Foundation. Total retail sales for prescription drugs filled at pharmacies. 2016. Available at: http://www.kff.org/health-costs/stateindicator/total-sales-for-retail-rx-drugs/?currentTimeframe $=0$ \&sortModel=\% 7B\%22colId\%22:\%22Location\%22,\%22sort $\% 22: \% 22$ asc\%22\%7D. Accessed February 11, 2018.

45. Chou R, Deyo R, Devine B, et al. The effectiveness and risks of longterm opioid treatment of chronic pain. Evidence Reports/Technology Assessments, no. 218. Agency for Healthcare Research and Quality. Rockville, MD. September 2014. Available at: https://www.ncbi.nlm.nih.gov/ books/NBK258809/. Accessed February 11, 2018.

46. Cepeda MS, Fife D, Chow W, Mastrogiovanni G, Henderson SC. Opioid shopping behavior: how often, how soon, which drugs, and what payment method. J Clin Pharmacol. 2013;53(1):112-17.
47. Katz N, Panas L, Kim M, et al. Usefulness of prescription monitoring programs for surveillance - analysis of Schedule II opioid prescription data in Massachusetts, 1996-2006. Pharmacoepidemiol Drug Saf. 2010;19(2):115-23.

48. Levy B, Paulozzi L, Mack KA, Jones CM. Trends in opioid analgesic-prescribing rates by specialty, U.S., 2007-2012. Am J Prev Med. 2015;49(3):409-13.

49. Gonzalez AM 3rd, Kolbasovsky A. Impact of a managed controlledopioid prescription monitoring program on care coordination. Am J Manag Care. 2012;18(9):516-24.

50. Haegerich TM, Paulozzi LJ, Manns BJ, Jones CM. What we know, and don't know, about the impact of state policy and systems-level interventions on prescription drug overdose. Drug Alcohol Depend. 2014;145:34-47. 


\begin{tabular}{|c|c|c|c|}
\hline APPENDIX A & \multicolumn{3}{|c|}{$\begin{array}{l}\text { Use of Other Types of Insurance } \\
\text { Among 21,538 Patients Making Cash } \\
\text { Payments for Opioid Prescriptions at } \\
\text { Rhode Island Retail Pharmacies } \\
\text { in } 2015\end{array}$} \\
\hline I & & Number o & Patients (\%) \\
\hline \multicolumn{2}{|c|}{ Cash payment for all opioid dispensings } & $16,24 \mathrm{C}$ & $(75.40)$ \\
\hline \multicolumn{2}{|c|}{$\begin{array}{l}\text { Cash plus only } 1 \text { other type of insurance } \\
\text { Cash plus } 2 \text { other types of insurance }\end{array}$} & 4,835 & $(22.45)$ \\
\hline \multirow{2}{*}{\multicolumn{2}{|c|}{$\begin{array}{l}\text { ash plus } 2 \text { other types of insurance } \\
\text { ash plus } 3 \text { other types of insurance }\end{array}$}} & & $(2.08)$ \\
\hline & & & $(0.07)$ \\
\hline
\end{tabular}

\begin{tabular}{l} 
APPENDIX B \\
$\begin{array}{l}\text { List of Medications Classified as } \\
\text { "Other" Under Opioid Medication } \\
\text { Types in Tables 1, 2, and 3 }\end{array}$ \\
\hline Medications \\
\hline Acetaminophen with codeine \\
\hline Anhydrous morphine (Paregoric) \\
\hline Brompheniramine, codeine with phenylephrine \\
\hline Butalbital, acetaminophen, caffeine with codeine phosphate \\
\hline Butalbital, aspirin, caffeine with codeine phosphate \\
\hline Cadsoprodol, aspirine and codeine phosphate \\
\hline Hydrocodone bitartrate with homatropine methylbromide \\
\hline Hydrocodone with chlorpheniramine \\
\hline
\end{tabular}

